\title{
La reorientación y la revitalización de los gobiernos locales en España *
}

José Manuel Canales Aliende **

\section{Introducción y planteamiento general}

El título de esta exposición estimo de entrada que sitúa claramente al lector sobre la finalidad y contenido de la misma, ya que ésta responde a una preocupación y a un debate de carácter general, si bien con las características añadidas de cada realidad nacional, en todos los países del mundo, y con mayor intensidad en los occidentales.

No sólo el fin del milenio es proclive a una reflexión de lo sucedido y a un buen propósito de enmienda, y parece que es el momento adecuado para ello; sino que, también y sobre todo, el nuevo entorno condicionante, los nuevos acontecimientos y problemas de ámbito mundial conducen de forma necesaria e inevitable a ello.

En la década de los ochenta y de los noventa, fundamentalmente en los países occidentales, se experimentaron procesos diversos, con desigual resultado, de modernización gubernamental y administrativa ', llegando a ser paradigmática en los últimos años la obra de David Osborne y Ted GAEBler La reinvención del Gobierno?.

En la actualidad, no se trata por el contrario de crear o de institucionalizar los gobiernos locales y sus Administraciones Públicas dependientes, sino de fortalecerlos y de darles una nueva orientación, y de analizar y cuestionar sus actividades y los servicios públicos que prestan, y cómo los prestan a los ciudadanos. No se pretende hoy ni que los Gobiernos locales hagan todo, como posible postura extrema, o la contraria fruto de la concepción neoliberal, de que la modernización ahora consiste sólo en simplemente recortar gastos ${ }^{3}$; sino de lo que se trata es que, fruto del análisis y de la evaluación ${ }^{4}$, reflexionen sobre lo qué pueden hacer, y cómo lo pueden hacer mejor, estableciendo prioridades negociadas con la sociedad civil y los diversos actores pólíticos, sociales y económicos ${ }^{5}$, potencien su capacidad de estrategia, de dirección, de relación ${ }^{6}$, de elección de posibles alternativas, siempre al servicio del ciudadano? Por otro lado, hoy aparecen nuevos campos de intervención pública como el desarrollo económico local, la lucha contra la exclusión social, el medio ambiente, etc.

El giro actual o perspectiva de los Gobiernos locales no es tanto el de prestar muchos servicios públicos de forma directa, y a veces monopolísticamente, sino de ser auténticos Gobiernos en el sentido político del término, decidiendo e impulsando más que gestionando, y afrontando la prestación de aquellos servicios públicos que sea necesario, eso sí, con eficacia, calidad y eficiencia, a fin de estar legitimados no sólo por su origen electoral democrático, sino sobre todo por los resultados ${ }^{8}$.

Por otro lado, el contexto en el que se insertan y actúan los gobiernos locales ha cambiado sustancialmente en la actualidad, fruto de esta mundialización o globalización económica que repercute sin duda en el sistema político y social ${ }^{9}$ afectado y caracterizado el cambio además por una explosión de las nuevas tecnologías y de la información en lo que se ha venido en llamar "La era de la Información" " torno de crisis económica, nuevas forma de exclusión social y de adualización socialn, urbanización progresiva, envejecimiento de la población, aparición de nuevos movimientos sociales, tendencia al pensamiento único neoliberal ", entre otros factores destacables.

Y en ese nuevo contexto antedicho, el espacio es cada vez más urbano y con un predominio de la ciudad sobre el campo, siendo el medio rural una continuidad y una complementariedad de lo urbano, y algo no antagónico. 
El sistema de ciudades interrelacionadas, dentro de un espacio territorial regional planificado, y el papel de éstas básicamente como centros de producción y de prestación de servicios, de articulación y organización social, y de generación de conocimientos, caracterizará sin duda al próximo siglo.

La posible tensión entre lo local y lo global no es tal, sino que lo que se produce en la "Aldea Global" de hoy es una complementariedad entre ambos aspectos. La vuelta a lo local, el llamado nuevo localismo democrático ${ }^{12} \mathrm{o}$ el fortalecimiento de la democracia local ${ }^{13}$ son aspectos y consecuencias de esta simbiosis.

Las ciudades tienen hoy un protagonismo mayor en lo económico, social y en lo político, pudiéndose hablar de ellas como actores sociales complejos y multidimensionales" ${ }^{14}$, que no pueden ni deben confundirse con los gobiernos locales, sino que su relación y papel con respecto a éstos es el de la colaboración y la participación en los procesos decisionales, y en su caso en la ejecución de las políticas públicas y en la prestación de varios servicios públicos a través de las vías varias posibles.

Los principales retos actuales de las ciudades son hoy básicamente los siguientes: 1) el desarrollo económico y urbano dentro de la planificación y la ordenación urbana de ámbito regional (o autonómico en la terminología española); 2) la consolidación y potenciación de las infraestructuras urbanas, en particular de carreteras, transportes públicos y comunicaciones; 3) la calidad de vida y la defensa del medio ambiente; 4) la cohesión e integración social, y la lucha contra las nuevas manifestaciones de la marginación y la exclusión social; y 5) la unueva Gobernabilidad".

La nueva Gobernabilidad, en el contexto antes señalado de globalización y complejidad, pretenderá dar respuesta a los nuevos retos, problemas y demandas de la ciudadanía y de la sociedad civil. La Gobernabilidad actual demanda que ésta aumente su capacidad de acción y de relación con los diversos actores sociales y políticos, para alcanzar más legitimidad, y a la vez una mayor y mejor representación, participación y democratización. La Gobernabilidad local hoy supone además una consideración de la misma en el contexto más amplio de la crisis y el replanteamiento del Estado ${ }^{15}$. Por otro lado, la democratización y la participación mayor de la sociedad civil en los gobiernos locales implica una mejor articulación complementaria y un fortalecimiento, necesario sin duda, de la misma.

La crisis del Estado actual es compleja, diversa, y tiene múltiples manifestaciones o aspectos: fiscal, territorial, del bienestar o social; $y$, como se ha dicho, plantea una nueva consideración del mismo, y dentro de él y del sistema político-administrativo de cada país deberá insertarse, y resolverse el nuevo papel y las características de los gobiernos locales. La búsqueda de un nue- vo modelo de Estado implica y condiciona, por tanto, a los gobiernos locales.

Se ha señalado, intentando sintetizar la nueva situación y retos del Estado, que el Estado-Nación es demasiado pequeño para los grandes problemas de la vida, y demasiado grande para los pequeños problemas de cada dia ${ }^{16}$.

Esta crisis del Estado no implica ni conlleva, contra lo que pudiera parecer, a su desaparición, sino a una reconsideración y reorientación del papel y actuación del Estado. Es más, tanto el Estado de Derecho como el Estado social, podemos decir que son un valor, una conquista irreversible e irrenunciable de las sociedades y democracias contemporáneas. Buscar unuevas orientaciones" y el nuevo papel del Estado en las sociedades actuales postindustriales, postmodernas, postcapitalistas y globalizadas, no es postular su destrucción, ni su desfiguración, sino reformarlo para precisamente hacerlo viable y mantenerlo ${ }^{17}$.

La proximidad ciudadana y la necesidad de la descentralización y delegación político-administrativas, dentro del nuevo modelo de reforma del Estado, hacen además que hoy se demande la potenciación de los gobiernos locales. Así, hoy los procesos de globalización y de descentralizacióbn serán paralelos y complementarios. Lo cual no se contrapone, sino que se complementa, y se presenta como alternativa viable y necesaria, para la globalización y la descentralización, si bien en un contexto y perspectiva diferentes, dadas las múltiples relaciones de interdependencia existentes con otros gobiernos e instituciones politico-admministrativas. La perspectiva de las Relaciones intergubernamentales e interadministrativas ${ }^{18}$ resulta pues hoy una realidad ineludible.

Ahora bien, la transformación, potenciación, reorientación, actualización y democratización de los gobiernos locales, no puede ni debe basarse en algo puramente formal a través del cambio normativo ${ }^{19}$, ni convertirse en una moda democrática del marketing político, sin un contenido real. Como ha señalado Alain Touraine "... la democracia actual no discurre solamente en leyes, sino sobre todo en una cultura política. La cultura democrática ha sido definida a menudo por la igualdad, ... exigiendo tres dimensiones básicas: respeto a los derechos fundamentales, ciudadanía y representación, y no pudiendo existir a su vez sin .... una reconstrucción del espacio público y sin una vuelta al debate político" ${ }^{20}$.

En el contexto de la globalización, y de la crisis múltiple y variada del Estado y del sector público, van a aparecer también hoy otras variables influyentes en el proceso, a saber entre otras: la privatización del sector público, la desregulación, la irrupción y potenciación de las ONG, nuevos movimientos sociales, nuevos problemas y fenómenos sociales.

Habría que resaltar respecto a lo anterior que si bien la privatización del secior público, y en particular del sector público 
empresarial, es una tendencia universal (si bien diferente y diferenciada en cada realidad nacional), ello no implica ni que sea siempre la panacea ni la única solución posible. El mercado no puede ni debe sustituir a lo público: cuestión distinta es nuevo planteamiento no antagónico de la relación, y de la interdependencia complementaria entre lo público y lo privado.

Los gobiernos locales, por otro lado, presentan una realidad muy plural y diversa, en función de sus circunstancias, historia, realidad, y sobre todo del modelo y características de la sociedad y del sistema político-administrativo en el que se insertan y actúan.

La doctrina ha resaltado la dificultad de precisar lo que se entiende en Europa por gobierno local, ya que existen realidades diferentes, pudiéndose señalarse, según STOKER, cuatro variables básicas para ello: a) la política; b) la administrativa; c) la situación interna; y d) el marco o entorno exterior ${ }^{21}$.

Las características más especificas de los gobiemos locales y de las políticas públicas locales, mencionadas por Joan SUBIRATS ${ }^{22}$, siguiendo a P. SAUNDERS, vendrán, en cada supuesto, determinadas por los cuatro aspectos siguientes: a) la confirmación y la estructura de los niveles de gobierno y de Administración Pública de cada Estado; b) las distintas funciones y modos de intervención administrativa; c) las diferentes formas de mediación y de relación política entre los distintos procesos y grupos sociales; es decir; el grado y forma de desarrollo del pluralismo social de ámbito local; y d) el grado de diferenciación y de conflicto ideológico existente entre las diferentes fuerzas políticas y sociales.

\section{Breve diagnóstico de la situación actual española}

Como he tenido ocasión de poner de manifiesto en otra publicación precedente ${ }^{23}$, el subsistema político-administrativo espanol, inspirado (aunque no totalmente) en el modelo continental francés de origen napoleónico, se podría sintéticamente caracterizar por las cinco notas siguientes: 1) pluralidad; 2) complejidad; 3) interrelación horizontal y vertical; 4) fragmentación; 5) apertura, es decir, en proceso de cambio.

El modelo español complejo, plural y diverso, se ve hoy por un lado regulado y configurado normativamente de un modo uniforme; y, en segundo término, se ve limitado y condicionado por la actitud y actuación "neocentralista" de las Comunidades Autónomas; y ello en un contexto y con varios retos de múltiples aspectos, entre los que podríamos citar los siguientes:
1) la consolidación de un modelo definitivo de Estado, propugnándose por muchos actores y fuerzas políticas como el más adecuado el federal;

2) un ámbito políico supranacional, cual es el de lid Uninứi Europea, que implica una nueva configuración y reordenación de la actuación de los poderes públicos para aplicar el principio de subsidiariedad ${ }^{24}$;

3) la posible reforma constitucional, y de las instituciones político-administrativas ${ }^{25}$, para su mayor actualización, modemización y democratización;

4) la mayor demanda de cercanía y de calidad en la prestación de los servicios públicos por parte de los ciudada$\operatorname{nos}^{26}$;

5) la búsqueda de mayor democracia participativa en todos los ámbitos, y en particular en el local;

6) la devolución de un mayor protagonismo a la vida local y a los gobiernos locales, a través fundamentalmente de la puesta en práctica del llamado ePacto Local ${ }^{27}$;

7) la crisis económica, y en particular la crisis económicofinanciera de los gobiernos locales y el déficit de sus Haciendas;

8) la necesidad de profundizar en la carencia de capacidad relacional, de negociación, de colaboración y de coordjnación; no sólo con los actores sociales y políticos de su localidad, sino también con otros Gobiernos y Administraciones de distinto ámbito territorial (estatal, autonómico, provincial, municipal);

9) la falta de una cultura política democrática de carácter local, fuertemente arraigada; y al margen de la mera participación en las elecciones locales;

10) la ausencia generalizada de un liderazgo político institucional y personal en los gobiemos locales;

11) la falta, salvo excepciones, de planificación estratégica y de procesos de innovación administrativa ${ }^{28}$;

12) la falta de una profesionalización, motivación, formación y retribución adecuada de los recursos humanos que prestan sus servicios en ellos;

13) la ausencia de una función pública directiva local, cualificada y neutral; y ello a pesar del papel importante de los Cuerpos con Habilitación Nacional;

14) la ocupación con vocacion gerencialista, amateur en ocasiones, por parte de la clase política de las funciones y tareas administrativas;

15) las políticas públicas locales, no adecuadas suficientemente al nuevo entorno y problemática actual ${ }^{29}$. 
Los gobiernos locales en España, intentando sintetizar la situación presente, podríamos decir que tienen una relevancia y protagonismo mayor que en la situación precedente del franquismo, en el que eran meras Administraciones locales; su papel e importancia en el sistema político español como un nuevo escenario, o "arena política" es un hecho ${ }^{30}$, y ello a pesar de su escasa consideración constitucional, aunque el hecho de que la Constitución de 1978 emplee por primera vez el término "Gobierno" y no sólo Administración Local es significativo, y creemos que implica una ruptura con el pasado. No obstante, aún no han alcanzado su pleno papel y protagonismo en el sistema político español, y menos aún en el reparto del gasto público total; ni tampoco han desarrollado suficientemente en su seno su capacidad de gobernar ${ }^{31}$ y de innovación administrativa al servicio de los ciudadanos. Existe en mi opinión un largo camino aún pendiente de recorrer, que no es imposible, pero sí que se presenta al menos con diversas y múltiples dificultades.

Los seis aspectos principales del cambio o atipologías de categorías de reformas", siguiendo a C.R. ALBA ${ }^{32}$, serían pues los siguientes: 1) estructurales; 2) funcionales; 3) financieros; 4) organizativos; 5) de procesos de decisión; 6) impositivas.

\section{Las perspectivas y posibles alternativas de cambio}

La situación presente, en el contexto y problemática señalados, aunque faltan ciertamente datos, creemos que puede y debe cambiarse sustancialmente. El problema y el reto es cómo, sin duda, y con qué éxito asegurado.

El cambio administrativo es difícil como ha señalado Guy Peters al decir que: “... Siempre que tratamos de predecir el futuro de gobernar o de la Administración Pública estamos condenados, de forma casi segura, al fracaso dada la complejidad de las interacciones entre las fuerzas sociopolíticas, al igual que por la naturaleza de cambio constante de las transformaciones tecnológicas. Factores tales como la expansión de las tecnologías de la información, el creciente multiculturalismo en casi todas las sociedades y el escepticismo de los ciudadanos con respecto al Gobierno, todo ello contribuye a crear un futuro muy incierto para el sector público... ${ }^{33}$.

Ahora bien, esa redefinición del papel y actuación de los gobiemos locales se realiza, como ha señalado Vincent WRIGHT ${ }^{34}$, dentro del marco más amplio de la redefinición de los Estados, estando ese proceso sometido a un conjunto de varias presiones convergentes y conflictivas; y lo anterior en un contexto mucho más amplio cual es el de la Unión Europea, la cual parece que avanza hacia un modelo de "Federalismo Flexible ${ }^{35}$. El federalismo europeo no puede ni debe implicar la desaparición de los Estados, sino tan sólo su modo de actuar y de relacionarse. La pertenencia a la Unión Europea postula, pues, una nueva articulación y distribución territorial del poder político y administrativo, en el que los gobiernos locales tendrán mayor protagonismo ${ }^{36}$ y ejecutarán de forma propia y/o delegada más servicios y políticas públicas; y en particular para aplicar eficazmente el principio de subsidiariedad.

La plena consolidación y desarrollo en la práctica del principio de la autonomía local, consagrado y garantizado tanto en nuestra Carta Magna como en la Carta Europea de la Autonomía Local ${ }^{37}$, hace imprescindible que no sólo se atribuyan más competencias en el sentido jurídico-local y que se le asignen mayores disponibilidades financieras hasta llegar al propuesto como ideal $25 \%$ del gasto público, sino que se articule un modelo de funcionamiento de los gobiemos locales en el que tengan en cuenta las relaciones intergubemamentales e intradministrativas de nivel horizontal y vertical, y en el que la cooperación y la colaboración con otros Gobiernos y Administraciones Públicas logre: una mejora de la gestion; una economía de escala; evitar las duplicidades administrativas; simplificar y racionalizar estructuras, procedimientos y servicios; la eficacia, la eficiencia y la calidad en los servicios públicos prestados y en las políticas públicas puestas en práctica.

Parece que uno de los instrumentos privilegiados para el logro de lo anterior es el "Pacto Local", habiendo propuesto una concreción del mismo el Gobierno de la Nación mediante el envío a las Cortes Generales de un proyecto de ley para ello ${ }^{38}$.

Junto a lo anterior, y a nivel macro, algunas de las soluciones y propuestas podrían ser las siguientes:

1) "Repolitizar" la vida y los gobiernos locales. Las decisiones políticas aparecen claves, frente a la precedente visión predominante de priorizar la prestación de servicios públicos ${ }^{39}$. Se trata de mejorar la capacidad de gobernar.

2) La revisión de la estructura de la organización de los gobiernos locales, haciéndose necesaria una clara diferenciación entre lo que es gobierno y dirección política y lo que es mera administración o gestión local. La confusión y la injerencia entre ambos niveles es periudicial ${ }^{40}$.

3) Descentralizar, delegar y desconcentrar los órganos administrativos, hasta llegar al máximo posible a la cercanía al ciudadano.

4) Potenciar, donde sea posible, el asociacionismo municipal, y los Consorcios, como fórmulas de cooperación y de colaboración institucional. 
5) Impulsar el liderazgo institucional de los gobiernos locales y el personal de sus presidentes, en particular de los alcaldes ${ }^{41}$.

6) Utilizar las Diputaciones Provinciales como gobiernos locales que favorezcan la cooperación intermunicipal, apoyando mediante nuevas fórmulas de fomento el desarrollo local.

7) Incrementar la presencia y la participación de los distintos actores políticos y sociales en los gobiernos locales, y hacer así que la democracia local sea no sólo representativa sino también "participativa* ${ }^{4 ?}$.

8) Reformar la legislación básica y de desarrollo local evitando el uniformismo existente. Las diversas tipologías de Entes Locales deben contemplarse, regularse y apoyarse.

9) Evitar el excesivo presidencialismo del Alcalde y potenciar el papel de la Comisión de Gobierno, como el auténtico "equipo" de gobierno local.

10) Cambiar la cultura política local, para adecuarla a la nueva realidad y papel de los gobiernos locales.

11) Reducir los Gabinetes y los puestos de asesoramiento político, con el status jurídico de personal eventual, al mínimo, para no interferir en la gestión que deben llevar a cabo los profesionales.

12) Incrementar el papel de "direcciónn y "orientación" de políticas del equipo de gobierno y de la Comisión de Gobierno.

13) Atribuir mayor protagonismo decisorio y de control a los Plenos.

14) Asegurar la presencia de los Grupos de la oposición en los órganos colegiados que se creen, para que ejerzan una tarea de representatividad y de control mayor.

15) Potenciar las Comisiones Informativas.

16) Crear Comisiones de Investigación.

17) Regular de forma más detallada y constructiva la moción de censura, a fin de asegurar la estabilidad del gobierno local.

18) Facilitar la transparencia de las decisiones y actuaciones de los gobiemos locales, garantizando la eficacia del derecho de información de los miembros de la oposición de los Entes Locales, así como de las asociaciones y de los ciudadanos.

19) El cambio de la actitud de los partidos políticos que, sin perder de vista la perspectiva nacional, deberán dar mayor importancia y concreción a la realidad y problemática local. Es decir, dar relevancia a la vida política local, frente a una orientación excesivamente "nacional".
20) Intentar dar respuestas a los nuevos problemas y demandas ciudadanas, evitando la atualización y la exchusión socials; promoviendo una mayor epersonalización y segmentación. de la prestación de los servicios públicos.

En cuanto a las tareas y políticas a llevar a cabo por los gobiernos locales, una vez superadas las etapas precedentes, dedicadas la primera a la adecuación de éstos a la nueva realidad política (1979-1985) y la segunda al desarrollo de las infraestructuras, equipamientos e inversiones necesarias (1986-1991) ${ }^{43}$; hoy sería necesario replantear, seleccionar y priorizar las actividades, políicas y los servicios públicos a prestar por cada gobiemo local. Se hace necesario no tanto intentar hacer muchas cosas, sino tan sólo llevar a cabo (directa o indirectamente) aquellas tareas, desarrollar aquellas políticas y prestar aquellos servicios públi$\cos$, que sea posible llevar a cabo bien. La cuestión y el reto es hacer bien, con eficacia y con calidad, aquello que se decida "estratégicamente" hacer.

La innovación, además de decisión, apoyo y voluntad política, necesita la negociación y la colaboración de los actores sociales y políticos, y de los recursos humanos que trabajan en la organización, así como requiere sin duda también una cierta prudencia y una gradualidad en su implantación. El idealismo y el entusiasmo precedente de los procesos modemizadores ha desaparecido bastante hoy, y se buscan sobre todo orientaciones y soluciones pragmáticas, viables y eficaces. En última instancia, la finalidad y la legitimidad vendrán dadas por el grado de satisfacción de la ciudadanía.

Pienso que es de aplicación al caso español lo planteado respecto a la situación norteamericana por David OSBORNE y Ted GAEBLER al decir: “... El gobierno municipal tendrá que realizar ciertos ajustes, y en cierto modo definirá más a menudo su función como la de un catalizador y un facilitador. Se descubrirá a sí mismo más en la función de definir problemas y de reunir luego recursos para que otros los utilicen en la solución de estos problemas.... El gobiemo municipal tendrá que dirigir más aún sus esfuerzos a entretejer los escasos recursos públicos y privados a fin de alcanzar las metas de nuestra comunidad..." ${ }^{44}$.

Hoy, pues, el papel de los gobiernos locales debe ser, además de cumplir las obligaciones mínimas de carácter legal, centrarse en desarrollar su capacidad estratégica, y en dirigir y fomentar, más que en intervenir directamente en la sociedad local. Las políticas públicas locales que decidan llevarse a cabo, diversificadas y complementarias, clentro de una adecuada y negociada planificación estratégica, deben ser de diferente contenido o de varias clases: estratégicas, administrativas, sociales, medioambientales y económicas ${ }^{45}$. El desarrollo local dentro de las "políticas urbanas" de la Unión Europea ${ }^{46}$, y la defensa del medio ambiente, junto a la lucha contra la pobreza y la marginación social, aparecen como tareas obligatorias y prioritarias, en las políticas públicas locales del futuro. 
Además de la dimensión estructural o "macro de las políticas públicas a desarrollar (propias, delegadas, o compartidas, según los casos), también aparece como un reto evidente, demandado y necesario, la transformación de la gestión pública local. A pesar de que los Gobiernos locales en España han sido pioneros, y los más exitosos en los llamados procesos de modernización administrativa llevados a cabo en la década de los ochenta y noventa en nuestro país, y ello a pesar de sus insuficiencias, como ha puesto de relieve Joan SuBIRATS ${ }^{47}$, la innovación de la gestión pública municipal sigue siendo una asignatura pendiente, porque este proceso además de complejo, difícil, lento y costoso, es también y sobre todo continuo.

La búsqueda y la aplicación de nuevas fórmulas de gestión de los servicios públicos locales aparece más que nunca como irrenunciable, ya que los ciudadanos exigen cada día más y mejores servicios públicos, y la proximidad de éstos hace que la presión sea mayor que en otras instancias y niveles de gobiernos territoriales.

El movimiento de la "nueva gestión pública" aparece pues con fuerza, como la ideología y la orientación de la reforma de la gestión local, pudiéndose señalar en mi opinión como los principales, no los únicos, instrumentos para la innovación en este ámbito, los siguientes:

a) La planificación estratégica, siendo los casos de Barcelona, Bilbao y Alcobendas paradigmáticos.

b) El Plan Director Local.

c) La distinción entre la provisión y la prestación de servicios públicos, y la búsqueda de eficacia y eficiencia en la gestión de éstos.

d) La "Calidad Total.

e) La Evaluación de Resultados.

f) La "Reingeniería de Procesos".

g) La aprobación de "Cartas” de servicios públicos locales.

Sin perjuicio de lo anterior, quisiera resaltar también que la innovación administrativa no puede llevarse a cabo con éxito sin apoyo político claro y continuo, y sin la colaboración del personal que trabaja en los gobiemos locales. El papel estratégico de los Recursos Humanos en cualquier organización es hoy un paradigma, y mucho más en el ámbito público. Hacen falta unas políticas de personal, no una mera administración de personal" ${ }^{48}$, en los gobiernos locales; y para ello nada mas idóneo que mejorar y adecuar los sistemas de selección y formación; mejorar e incentivar (no sólo en las retribuciones) al personal; y establecer un sistema objetivo de carrera administrativa, y dentro de ella la figura del directivo público local ${ }^{49}$, incorporando nuevos estilos de dirección y de gestión.

Pero si la innovación y la lucha contra la obsolescencia administrativa es una necesidad, un reto y una demanda, no puede olvidarse que los medios financieros pueden posibilitarlo; por lo que la reforma y la revitalización de las Haciendas Locales para solucionar el déficit estructural y progresivo de éstas aparece como imprescindible. La descentralización política y administrativa, no sólo en cuanto al contenido, debe incluir competencias y políticas a llevar a cabo; sino también participación en el gasto público estatal, subvenciones de los otros gobiernos territoriales (Unión Europea, Comunidad Autónoma), nuevos impuestos, fórmulas alternativas de financiación propias, recargos en los impuestos de carácter estatal y autonómico, etc.

La modernización administrativa debe abarcar a la totalidad de la estructura organizativa y actividades de los Gobiernos locales, y no debe ser sólo de "fachadan, simbólica" o de "ventanilla"; o creer que la modificación e introducción de la informática, como un elemento sectorial, lo es todo. La perspectiva y las innovaciones macro deben completarse con las micro; no produciendo además la "esquizofrenia" de la existencia de "culturas" contrapuestas.

La modernización o innovación administrativa no es sólo un cambio o una mejora del funcionamiento y de la prestación de los servicios públicos, sino que es también una transformación y una nueva cultura de la gestión pública local, en base a un modelo y paradigma "postburocrático".

Para finalizar, quisiera citar un texto de Nicolás de MAQUIAVELO, que me parece muy expresivo del reto y de la problemática expuesta: "... No hay cosa más dificil de tratar ni de éxito más dudoso, ni más difícil de manejar, que ponerse al frente de la introducción de nuevas órdenes; porque el introductor tendrá por enemigos a todos aquellos que les va bien con las órdenes viejas, y hallará tibios defensores entre aquellos a quienes les irá bien con las órdenes nuevas..." ${ }^{50}$.

\section{Notas}

- Ponencia presentada en el III Congreso Internacional del CLAD, sobre Reforma del Estado y de la Administración Pública, celebrado en Madrid en octubre de 1998.
- Profesor Titular de Ciencia Políica y de la Administración de la Universidad Com. plutense de Madrid. 
1 Véase en ese sentido, y como un resumen de la evolución y de la situación: OCDE, La transformación de la gestión priblica. Las reformas en los paises de la OCDE. Traducción y publicación del MAP y del BOE. Madrid, 1997.

'David OsBorne y Ted GAEBLER, La reinuención del Gobiemo. La influencia del espiritu empresarial en el sector público. Ediciones Paidós. Barcelona. 1994.

'Es expresivo e inequívoco en sentido contrario el Informe Al GORE, Crear una Administración Priblica que funcione mejor y cueste menos. Informe del National Performance Review. Traducción del Instituto Vasco de Administración Pública. Vitoria, 1994. En su página 52 dice textualmente: ‘... Para reinventar el gobierno no es sólo cuestión de ajustar programas; es preciso cambiar también de forma radical el modo de operar en la Administración....

' Sobre la evaluación, existe una amplia y variada bibliografia, entre ella destacaría la siguiente: OCDE. Audit des performances et modermisation de l'Administration. Comité PUMMA. París, 1996; Carol H. Welss, Eualuation. Second Édition. Prentice Hall. New Jersey, 1998; Eric MONNIER, Evaluación de la acción de los poderes priblicos. Traducción y edición del Instituto de Estudios Fiscales. Madrid, 1995; Frans L. LeEvw; Ray C. RIST y Richard SONNICHSEN, Can governements learm? Comparative Perspectives on Evaluation $\mathcal{E}$ Organizational Leaming. Transaction Publishers. New Brunswick y Londres, 1994; Joan SUBIRATS, Análisis de politicas públicas y eficacia de la Administración. MAP. Madrid, 1989; etc.

Es de interés en este punto con carácter general: Michel Crozier, tLa posición del Estado ante los otros actores. en Gestión y Análisis de Políticas Públicas, n. ${ }^{9} 2$, eneroabril 1995, pp. 93 a 99. También referido al mundo local: Jordi Borja, Las Ciudades como actores políticoss en América Latina Hoy. Revista de Ciencias Sociales. Segunda Época, n.․ 15, Abril, 1997, pp. 15 a 20.

"La situación actual de complejidad, interdependencia y complementariedad, dentro de la perspectiva interorganizacional, hace que se califique al Estado también como - Relacional, en Xavier MENDOZa Mayordomo, .Técnicas Gerenciales y modemización de la Administración Pública en España en Documentación Administrativa, n.․ 223, Julio-Septiembre, 1990, pp. 261 a 290.

En ese sentido sigue siendo de actualidad la obra clásica: OCDE, La Administración al senvicio del priblico. Traducción y publicación del MAP y BOE. Madrid, 1988.

${ }^{\circledR}$ Véase en este sentido además de J.M. CAvales ALLENDE, Gobiemo Local y Democracia. en Revista de Estudios de Administración Local y Autonómica, n. ${ }^{9} 270$, Madrid, Abril-Junio 1998, pp. 431 a 468; VARIOS AUTORES, -Veinte Años de Ayuntamientos Democráticos: El retomo de la Política Local. en Informe España 1997. Una interpretación de su realidad social. Fundación Encuentro Madrid, 1998; Quim BRuGute y Ricard Gomì (Coords.), Gobiemos Locales y políticas puiblicas. Ariel Editorial. Barcelona, 1998.

" Veáse en ese sentido para mayor detalle entre otros: Manuel CASTELS, La era de la información. 3 volúmenes. Alianza Editorial, Madrid, 1996; Jordi Borja y Manuel CasTELLS, Local y Global. La gestión de las ciudades en la era de la información. Editorial Taurus. Madrid, 1997.

1. Así, entre una amplia bibliografia, José B. TERCEIRo, La sociedad digital. Del homo sapiens al homo digitalis. Alianza Editorial. Madrid, 1997; Giovanni SARTORI, Homo videns. La sociedad teledinigida. Editorial Taurus. Madrid, 1997; Juan-Luis CEBRIÁN, La red. Cómo cambiarán nuestras vidas. Los nuevos medios de comunicación. Editorial Taurus. Madrid, 1998; Luis JOYANES, Cibersociedad. Los retos sociales ante un nuevo mundo digital. MacGraw-Hill. Madrid, 1997; etc.

"Una exposición sintética y crítica de esta tendencia, entre otros en Joaquín EsTEFA. NÍA, Contra el pensamiento único. Prólogo de Alain TOURAiNe y Epilogo de Sami Nalr. Editorial Taurus. Madrid, 1997.

12. Quim BruGuÉ y Ricard Gomà, en la página 18 de la obra antes citada Gobiemos Localés y políticas públicas, señalan que: -... se abren las puertas también a nuevo localismo donde el rol de los gobiernos locales experimenta un fuerte impulso debido fundamentalmente a la diversificación de las demandas sociales y a la globalización de la economía.... También puede verse: Clemente J. NAVARRO YáNEz. El nuevo localismo democrático: análisis descriptivo de algunas tendencias. en Gestión y Análisis de Politicas Públicas, n.9 9, Mayo-Agosto de 1997, pp. 95 a 103.

1" Véase también entre otros, además de las referencias del texto y bibliografia de mi artículo antes citado: J.M. CANALES ALIENDE, Gobierno Local y Democracia, así como la bibliografía de las notas precedentes: Desmond KING y Gerry STOCKER, Rethinking Local Democracy. MacMillan. Londres, 1996.

14 Jordi BorJa, - Llas ciudades como àctores políicos., ob. cit., p. 15. También del mismo autor, la obra conjunta con Manuel CASTELLS antes citada Local y Global. La ges- tión de las ciudades en la Era de la Información. Además, entre otros, Xavier ARBOS y Salvador GINER, La gobernabilidad. Ciudadania y democracia, en la encrucijada mundial. Siglo Veintiuno de España Editores, S.A., Madrid, 1993

1: Sobre la crisis del Estado, existe una amplia y variada bibliografia, no obstante destacaria además de lo referente a esta cuestión: OCDE, La transformación de la Gestión priblica. Las reformas en los países de la OCDE, ob. cit.; BAvCO MUNDLAL, El Estado en un mundo en transformación. Washington D.C., 1997; Guy PETERS, Gestionando un Estado Vaciados en lecturas de Gestion Puiblica. Selección de textos por Quim BRUGUE y Joan SuBIRATS. MAP y BOE. Madrid, 1996, pp. 403 a 418; Vincent WriGrT, -Redefiniendo el Estado: las implicaciones para la Administración Pública. en Gestión y Análisis de Politicas Püblicas, n. ${ }^{\text {78 }}$ 7.8. Madrid, Septiembre, 1996-Abril, 1997, pp. 27 a 44; VARIOS AưTORES, El papel del Estado hoy. Economistas, 1997; n.. 75, Año XV Número monográfico de Temas para el Debate, n. ${ }^{4} 40$. Madrid, marzo de 1998; etc.

in Asi, entre otros, David Heid, La democracia y el orden global. Del Estado moderno al Gobierno cosmopolita. Editorial Paidós. Barcelona, 1997.

1. Ésta es la tesis que desarrolla ampliamente, entre otros, la obra de: Santiago Mu Noz Machado; José-Luis Garcia DegGado y luis González Seara, las Estructuras del Bienestar, Derecho, Economia y Sociedad en España. Escuela Libre Editorial y Editorial Civitas, S.A. Madrid, 1997.

is Entre una amplia bibliografia puede verse: Francesc Morata, Políticas Públicas y relaciones intergubernamentales. en Documentación Administrativa, $n .{ }^{\text {. }} 224-225$, octubre 1990-marzo 1991, pp. 153 a 166; Robert AGRaNOFF, LLas relaciones y la gestión intergubernamentales en Rafael Bavón y Ernesto Carrillo (Comps.), La Nueva Administración Pública. Alianza Universidad Textos. Madrid, 1997, pp. 125 a 170.

${ }^{19}$ En este sentido es ya clásica la obra de Michel CROzIER, No se cambia la sociedad por Decreto. Traducción del INAP. Madrid, 1984.

9" Alain Touralne, Crítica de la modernidad. Ediciones Temas de Hoy, S.A. Madrid, 1993, pág. 6.

2* Quim BruguE, ·Teorias sobre Govern local: un repas a las aproximacions mas destacables de la decada dels 80. en Govern local. Departament de Ciencia Política i Dret Public. Universitat Autonoma de Barcelona. Anuari 1997, p. 27.

" Joan SuBiRaTs, Gobiemo Local y Políicas Públicas. Agentes en la España de los 90 . en Recista Valenciana de Estudis Autonomics, n. ${ }^{9}$ 15, Febrero-Mayo de 1996, pp. 17 a 26.

3 En ese sentido y entre una amplia bibliografía ya citada, puede verse en concreto y monográficamente: José Manuel CANALES ALIENDE, -Gobiemo Local y Democracia. ob. cit., p. 439.

"En ese sentido, además de una amplia bibliografia sobre el principio de subsidiariedad, véase Carlos Alonso ZndDivar y Manuel Castells, España fin de siglo. Prólogo de Narcís SERRA. Alianza Editorial. Madrid, 1992. Especialmente pp. 166 a 172, 178 a 179.

$\because$ Sobre la reforma de la Constitución puede verse por todos: G. JeluNEK, Reforma y mutación de la Constitución. Estudio Preliminar de Pablo LuCAS Verdú. Traducción de Christian FOORSTER. Centro de Estudios Constitucionales. Madrid, 1991. Sobre la reforma de las Instituciones político-administrativas es de gran interés la visión de conjunto de Luis González SEARA, Reforma y regeneración política en España. en Praxis Sociológica, n. ${ }^{2}$ 2. Universidad de Castilla-La Mancha. Facultad de Ciencias Jurídicas y Sociales. Toledo, 1996 , pp. 83 a 92

* La calidad en la prestación de los servicios públicos constituye hoy un paradigma de la nueva gestión pública. Véase como más significativa, entre una variada bibliografia, la siguiente: Rafael BANON MARTíNEZ (Director), La productividad y la calidad en la gestion priblica. Xunta de Galicia. EGAP. Santiago de Compostela, 1996; y Cristopher POLT y Geert BOUCKAERT, Quality Improvent in European Public Services. Concepts, Cases and Commentary. Sage Publications. London, 1995.

$\because$ Sobre el Pacto Local, entre una reciente bibliografia, puede verse: José-Manuel $C_{A}$ NAIES AUENDE, Una aproximación a la filosofia del pacto Local. Actualidad Administrativa, ${ }^{8}{ }^{2} 25$. Semana del 16 al 22 de junio de 1997 , pp. 441 a 452.

* Sobre la Nueva Gestión Pública, y la modemización administrativa a nivel local puede verse: Hervé SERIEYX, El Big Bang de las Organizaciones. Ediciones B de Management. Grupo Z. Barcelona, 1994; VARIOS AuTORES, Nueva Gestión Local. Moldermización Local en Alcobendas (1). Editorial Popular. Madrid, 1993; AYuNTAMIENTO DE ALCOBENDAS, Calidad y modernización en la gestión puiblica. Ediciones Gestión 2000, S.A. y Ayuntamiento de Alcobendas. Madrid, 1992 
- Sobre las políticas públicas locales, puede verse: José-Manuel CAvalEs ALENDE, - Nuevo entomo y perspectiva de las políicas públicas locales. en Revista Aragonesa de Administración Pública, n. ${ }^{\circledR} 11$, Diciembre de 1997, pp. 287 a 315.

"Véase en este senuido la importante y novedosa obra colectiva dirigida por Carlos K. ALRA y Francisco J. V.VACLOCHA, El sistema político local: un nuevo escenario de Gobiemo. Universidad Carlos III de Madrid y BOE. Madrid, 1997.

"Sobre la capacidad de gobernar, me remito a la paradigmática obra de Yehezkel DROR, La capacidad de gobernar. Informe al Club de Roma. Ediciones Galaxia Gutemberg y Círculo de lectores. Barcelona, 1994.

"En Carlos R. AlBa, Gobiemo Local y Ciencia Política: Una aproximación, en la obra dirigida y ya citada precedente de este autor con Francisco J. VANACLOCHA, El sistema políico local: un nuevo escenario de gobierno.

"Guy PETERS, Futuras alternativas para la Administración Pública. en Gestión y Análisis de Politicas Públicas, n." 7-8, Septiembre, 1996-Abril, 1997, p. 5.

:Vincent WRIGHT, Redefiniendo el Estado: las implicaciones para la Administración Pública. cit. supra.

"Ses Metcalfe, Federalismo flexible. en Gestión y Análisis de Políticas Públicas, n." 7-8, septiembre 1996-abril 1997, pp. 45 a 60.

4. Sobre este punto puede verse entre otros: José-Manuel CANales AlJENDE, El Pacto Local en el marco de la Unión Europea. en V Jornadas Galegas sobre Economia das Corporacions Locais. Xunta de Galicia. Santiago de Compostela, 1997, pp. 203 a 234; y el número extraordinario de Julio de 1998 de CUNAL. Revista de Estudios Locales, publicada por el Consejo General Nacional de Funcionarios de Administración Local con Habilitación de Carácter Nacional.

- Véase para mayor detalle la obra excelente monográfica de José-Manuel RoDRíguez Álvarez, La Carta Europea de la Autonomia Local. Bayer Hnos. Editorial, S.A. Barcelona, 1996.

« Proyecto de Ley aprobado en el Consejo de Ministros el 17 de julio de 1998.

4) Así, Josep María VALLÉS en la presentación de la obra antes citada de Quim BRUGUÉ y Ricard GOMA (Coords.), Gobiemos Locales y políticas priblicas, p. 9.
" En ese sentido el antes citado Informe España 1997. Una interpretación de su realidad social de la Fundación Encuentro. Especialmente pp. 487 y ss.; como el Informe Pi i Sunyer sobre el Gobiemo Local en España. Barcelona, 1997.

"Véase Lourdes LOPEz NIETO, Reflexión sobre los Gobiemos Locales: Opiniones de los Funcionarios Directivos y los Alcaldess en CUNAL. Revista de Estudios Locales. Publicación del Consejo General Nacional de Funcionarios de Administración Local con Habilitación de Carácter Nacional, n. ${ }^{2}$ 21, Mayo-Junio, 1998, p. 47.

'- En ese sentido y entre una amplia bibliografía el arículo de J.M. CANALES ALIENDE, - Gobiemo Local y Democracia, ob. cit.

"Para mayor detalle véase: Jordi López CampS y Albert Gadea CARRERA, El control de gestión en la Administración Local. Ediciones de Gestión 2000, S.A. Barcelona, 1992.

"David OsBorve y Ted GAEBlER, La reinvención del Gobierno. La influencia del espiritu empresarial en el sector público. Editorial Paidós. Barcelona, 1994, p. 57.

is Véase en este sentido: José-Manuel CAvalES, Nuevo entomo y perspectivas de las políticas locales, ob. cit

" Para mayor detalle, véase el reciente arículo de Manuel Arevilla SáeZ, Las Políticas Locales Europeas o el Desarrollo Integrado como Método. en el $n^{2}$ extraordinario de julio de 1998 antes citado de CUNAL. Revista de Estudios Locales, pp. 9 a 32.

". Joan Subirats, en el capítulo IV. .Con esta Administración, ipodremos sostenemos en Europa?. en el Informe España 1997. Una interpretación de su realidad social Fundación Encuentro. Madrid, 1998. Especialmente pp. 316 y ss.

is En este sentido: Joan PraTs, Política, gestión y administración de recursos huma nos en las Administraciones Públicas. en Documentación Administrativa, n. ${ }^{\circ} 210$ 211, mayo-septiembre de 1987, número monográfico sobre sla carrera administrativa. pp. 121 a 134. Véase también el n." 241-242, de enero-agosto de 1995 de esta Revista, monográfico -sobre la renovación del sistema de mérito y la institucionalización de una función directiva en Espaǹa.

"Sobre esta figura, me remito a José-Manuel CAvales ALIENDE, EEl directivo público. en Actualidad Administrativa, n. 7 . Semana del 11 al 18 de febrero de 1996, pp. 151 a 161 .

" Nicolás de Maquiavelo, El Príncipe. La estrategia del líder. Prólogo de Sabino FERNÁNDEZ CAMPO y edición de Mercedes López SuÁrEz. Ediciones Temas de Hoy. Madrid, 1994. 